\title{
Damage Detection Technique for Cold-Formed Steel Beam Structure Based on NSGA-II
}

\author{
Byung Kwan Oh, ${ }^{1,2}$ Se Woon Choi, ${ }^{3}$ and Hyo Seon Park ${ }^{1,2}$ \\ ${ }^{1}$ Department of Architectural Engineering, Yonsei University, Seoul 120-749, Republic of Korea \\ ${ }^{2}$ Center for Structural Health Care Technology in Building, Yonsei University, Seoul 120-749, Republic of Korea \\ ${ }^{3}$ Department of Architecture, Catholic University of Daegu, Gyeongsan-si 712-702, Republic of Korea \\ Correspondence should be addressed to Hyo Seon Park; hspark@yonsei.ac.kr
}

Received 2 June 2015; Accepted 16 July 2015

Academic Editor: Yeesock Kim

Copyright (C) 2015 Byung Kwan Oh et al. This is an open access article distributed under the Creative Commons Attribution License, which permits unrestricted use, distribution, and reproduction in any medium, provided the original work is properly cited.

Cold-formed steel is uniform in quality, suitable for mass production, and light in weight. It is widely used for both structural and nonstructural members in buildings. When it is used in a bending structural member, damage such as local buckling is considered to be more important than general steel members in terms of failure mode. However, preceding studies on damage detection did not consider the failure characteristics of cold-formed beam members. Hence, this paper proposes a damage detection technique that considers the failure mode of local buckling for a cold-formed beam member. The differences between the dynamic characteristics from vibration-based measurements and those from finite element model are set to error functions. The error functions are minimized by the optimization technique NSGA-II. In the damage detection, the location of local damage and the severity of damage are considered variables. The proposed technique was validated through a simulation of damage detection for a coldformed steel beam structure example.

\section{Introduction}

Sensor-based structural health monitoring (SHM) studies for assessing the safety of building structures are actively ongoing. Research has been carried out at the structural member level [1-3] and the entire system level of the building structure $[3,4]$ using various sensors. The results are then applied to real buildings to assess their safety. In addition, studies have focused on identifying the system of structures $[5,6]$, updating models [7], and detecting damage [8,9], using the information obtained from SHM.

Cold-formed steel members are widely used in various industrial fields including building construction, where it is employed for the light joist floors, secondary structural members, and light partition walls of tall buildings. These cold-formed members have a collapse mechanism different from that of typical structural members. When a coldformed member is used as a bending member, local buckling such as web crippling is an important collapse mode [10]. Accordingly, the design standards are different from those for typical structural members, and related studies [11] are ongoing.
Because cold-formed members have characteristics different from those of a typical structural member for failure mechanism, existing damage detection techniques are not suitable for application. Accordingly, this paper proposes a damage detection technique that considers the failure mode of a cold-formed member. The proposed technique searches locations and severities of local buckling, which is a major failure mode of cold-formed member. Based on the measured dynamic characteristics of the structure, parameters such as the local buckling location and severity are searched using model. NSGA-II [12], which is one of the optimization techniques, is employed to minimize the error functions between the measurements and model. The proposed technique was validated through the simulation of damage detection for a cold-formed steel structural member.

\section{Damage Detection Method}

The proposed damage detection technique is based on vibration measurement and finite element (FE) model updating. Through measurements of the vibration for the structure 
TABLE 1: Parameter settings.

\begin{tabular}{lcc}
\hline Parameter $(X)$ & Damage location & Additional parameter $(X)$ \\
\hline 0 & No damage & - \\
1 & Left end in element & $0-\infty$ \\
2 & Right end in element & $0-\infty$ \\
3 & Both ends in element & $0-\infty$ \\
\hline
\end{tabular}

using the accelerometer, dynamic characteristics such as the natural frequency and mode shape are obtained. A model having characteristics similar to the measurements is constructed to detect damage. This study focuses on a coldformed steel beam structure and it is developed in an FE model. The model is split into a predetermined number of segments. When local buckling occurs at specific location, the rotational stiffness is assumed to be changed at the corresponding location to reflect the failure mode of the cold-formed steel beam structure. In this study, when local buckling occurred, the end of element of FE model is assumed to be turned into semirigid with a linear rotational stiffness rather than be a perfect fixed-end or pinned-end. Parameters in the damage detection process are set based on whether end of each element is semirigid or not and the rotational stiffness value, which is given when end is semirigid. As presented in Table 1, there are a total of four parameter values for each beam element: zero means that both ends are fixed, one means that the left end is semirigid, two means that the right end is semirigid, and three means that both ends are semirigid. When a semirigid element is chosen, a rotational stiffness value is additionally assigned as a parameter at corresponding point.

To minimize difference between dynamic characteristics from measurement and model, the dynamic characteristics of the model have to be extracted. The following multi-degreeof-freedom (MDOF) equation of motion is used for model:

$$
M \ddot{u}+C \dot{u}+K u=F(t) .
$$

The natural frequency and mode shape for each mode are calculated through an analysis of the eigenvalue using the mass and stiffness matrix constructed in the MDOF equation of motion. For the degree of freedom (DOF) of a cold-formed steel beam element, only the translational deflection and flexural rotation are considered. A consistent mass matrix is employed for the mass, and the stiffness matrix elements are configured as follows:

$$
K=\frac{E I}{L}\left[\begin{array}{cccc}
\frac{12}{L^{2}} & -\frac{6}{L} & -\frac{12}{L^{2}} & -\frac{6}{L} \\
-\frac{6}{L} & 4 & \frac{6}{L} & 2 \\
-\frac{12}{L^{2}} & \frac{6}{L} & \frac{12}{L^{2}} & \frac{6}{L} \\
-\frac{6}{L} & 2 & \frac{6}{L} & 4
\end{array}\right] .
$$

However, (2) cannot express the semirigid behavior of elements. Accordingly, when an element has semirigid
TABLE 2: Measured natural frequency.

\begin{tabular}{lc}
\hline Mode & Natural frequency $(\mathrm{Hz})$ \\
\hline 1 & 84.27 \\
2 & 277.33 \\
3 & 646.26 \\
\hline
\end{tabular}

rotational stiffness, a transformed stiffness matrix like (3) is used. Equation (3) is the stiffness matrix used when rotational stiffness is assigned because of damage that occurs on the left end of an element. In (4), $k$ is a rotational stiffness whose value changes linearly depending on $\alpha$. Consider

$$
\begin{aligned}
K & =\frac{E I}{L} \\
& {\left[\begin{array}{cccc}
\frac{12}{L^{2}}-\frac{36}{L^{2}} \frac{1}{\alpha+4} & \frac{6}{L} \frac{\alpha}{\alpha+4} & -\frac{12}{L^{2}}+\frac{36}{L^{2}} \frac{1}{\alpha+4} & \frac{6}{L}-\frac{12}{L} \frac{1}{\alpha+4} \\
\frac{6}{L} \frac{\alpha}{\alpha+4} & \alpha-\frac{\alpha^{2}}{\alpha+4} & -\frac{6}{L} \frac{\alpha}{\alpha+4} & 2 \frac{\alpha}{\alpha+4} \\
-\frac{12}{L^{2}}+\frac{36}{L^{2}} \frac{1}{\alpha+4} & -\frac{6}{L} \frac{\alpha}{\alpha+4} & \frac{12}{L^{2}}-\frac{36}{L^{2}} \frac{1}{\alpha+4} & \frac{12}{L} \frac{1}{\alpha+4}-\frac{6}{L} \\
\frac{6}{L}-\frac{12}{L} \frac{1}{\alpha+4} & 2 \frac{\alpha}{\alpha+4} & \frac{12}{L} \frac{1}{\alpha+4}-\frac{6}{L} & 4-4 \frac{1}{\alpha+4}
\end{array}\right], } \\
k & =\alpha \frac{E I}{L} .
\end{aligned}
$$

As explained above, after the dynamic characteristics of the model are obtained, the error functions are set with those obtained from the measurement. The error functions in (5) are minimized by NSGA-II. Then, the parameters set above are searched for. Consider

$$
F_{i}=\left|\frac{f_{i}^{\mathrm{me}}-f_{i}^{\mathrm{id}}}{f_{i}^{\mathrm{me}}}\right|+\left|1-\mathrm{MAC}_{i}^{\mathrm{me}, \mathrm{id}}\right| \quad \text { for } i=1 \text { to } n,
$$

where $f_{i}^{\text {me }}, f_{i}^{\text {id }}$, and $\mathrm{MAC}_{i}^{\text {me,id }}$ refer to the measured natural frequency, natural frequency from model, and modal assurance criteria, respectively.

\section{Application}

To validate the proposed damage detection technique, simulations for a cold-formed steel beam were conducted. Figure 1 shows the structures for the simulation, a C-type cold-formed beam (moment of inertia: $8.64 \times 10^{-6} \mathrm{~m}^{4}$, cross-section area: $2.37 \times 10^{-3} \mathrm{~m}^{2}$ ). Figure 1 shows the structure before damage; it was assumed to have a fixed-end condition by welding and bolting. The first three modes dynamic characteristics of the target beam were assumed to be measured with an accelerometer, as given in Table 2 and Figure 2.

3.1. Damage Case 1: Single Damage. In the first damage scenario, local buckling occurred $1 \mathrm{~m}$ from the left end of the beam, as shown in Figure 3. For the damage detection, the model of beam in Figure 1 was split into six elements. The joint between elements 1 and 2 was assumed to be transformed into a semirigid joint due to the local buckling. The damaged model was developed using rotational 


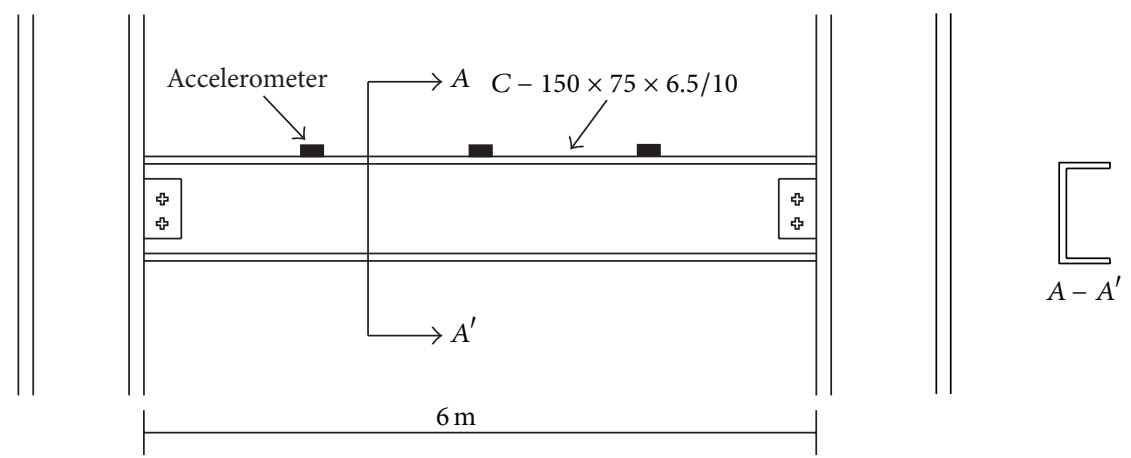

FIGURE 1: Target structure for damage detection.

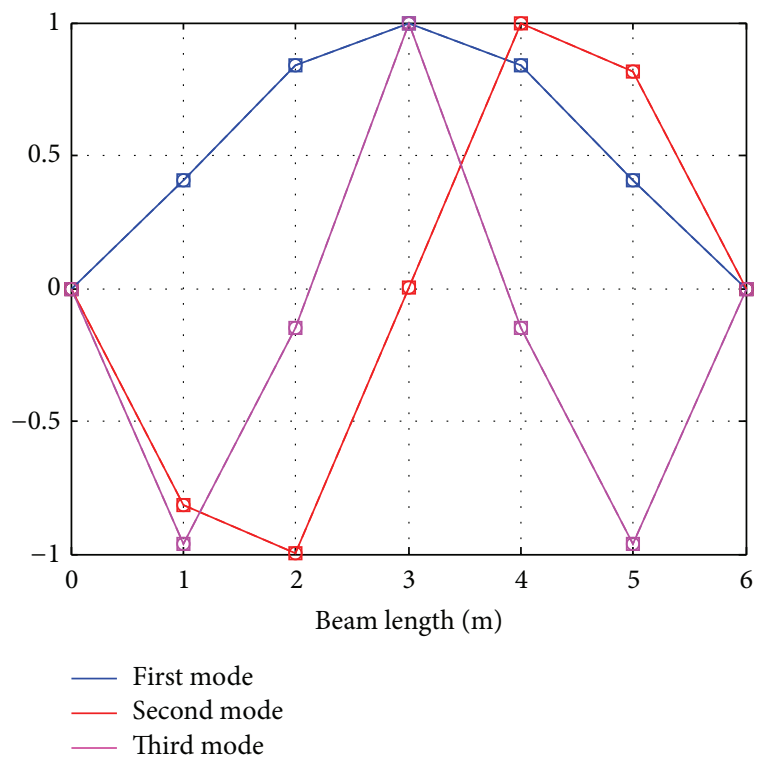

FIGURE 2: Mode shapes of undamaged structure.

spring at damaged location. The springs on the right end of element 1 and left end of element 2 were assumed to have linear rotational stiffness values of $295.20 \mathrm{kN} \cdot \mathrm{m} / \mathrm{rad}$ and $147.60 \mathrm{kN} \cdot \mathrm{m} / \mathrm{rad}$, respectively. These stiffness values represent the severity of damage.

The damage detection technique presented in Section 2 was applied. The damaged location between elements 1 and 2 is precisely identified. Furthermore, the rotational stiffness values at the damaged spot are identified, which is given in Table 3.

The damaged location and the severity of damage were updated in the model, and the modal parameters of the model and measurements were compared. The natural frequencies were confirmed to decrease for the damaged structure compared to those for the undamaged structure. Table 4 and Figure 4 present this comparison. It is confirmed that the modal parameters of the updated model matched the measured values.
TABLE 3: Assumed and identified rotational stiffness for single damage case.

\begin{tabular}{lcc}
\hline & $\begin{array}{l}\text { Rotational stiffness at } \\
\text { right end of element 1 }\end{array}$ & $\begin{array}{c}\text { Rotational stiffness at } \\
\text { left end of element 2 }\end{array}$ \\
\hline $\begin{array}{l}\text { Assumed values } \\
(\mathrm{kN} \cdot \mathrm{m} / \mathrm{rad})\end{array}$ & 295.20 & 147.60 \\
$\begin{array}{l}\text { Identified values } \\
(\mathrm{kN} \cdot \mathrm{m} / \mathrm{rad})\end{array}$ & 290.09 & 157.64 \\
Error $(\%)$ & 1.73 & -6.80 \\
\hline
\end{tabular}

TABLE 4: Comparison of natural frequencies from measurements and updated model for single damage case.

\begin{tabular}{lccc}
\hline & First mode & Second mode & Third mode \\
\hline Measurements (Hz) & 80.08 & 227.11 & 425.87 \\
Updated model (Hz) & 80.47 & 233.40 & 448.24 \\
Error (\%) & -0.48 & -2.77 & -5.25 \\
\hline
\end{tabular}

3.2. Damage Case 2: Multiple Damage. In the second damage scenario, local buckling occurred at two spots on the structure, as shown in Figure 5. Damage was assumed to occur at $1 \mathrm{~m}$ from the left end of the beam and $1 \mathrm{~m}$ from the right end of the beam. In the model, the right end of element 1 and left end of element 2 exhibited damage at $1 \mathrm{~m}$ from the left end of the beam through semirigid behavior. The rotational stiffness values at the right end of element 1 and left end of element 2 were assumed to be both $147.60 \mathrm{kN} \cdot \mathrm{m} / \mathrm{rad}$. In addition, the right end of element 5 and left end of element 6 exhibited damage at $1 \mathrm{~m}$ from the right end of the beam through semirigid behavior. The rotational stiffness values at the right end of element 5 and left end of element 6 were assumed to be both $147.60 \mathrm{kN} \cdot \mathrm{m} / \mathrm{rad}$.

Similar to Section 3.1, the local buckling damage was detected using the proposed damage detection technique presented in Section 2. The damaged locations were precisely detected, and the assumed rotational stiffness values were identified. Table 5 gives the identified rotational stiffness values; they were less precise than the detection results for single damage in Section 3.1. This was because identical solution 

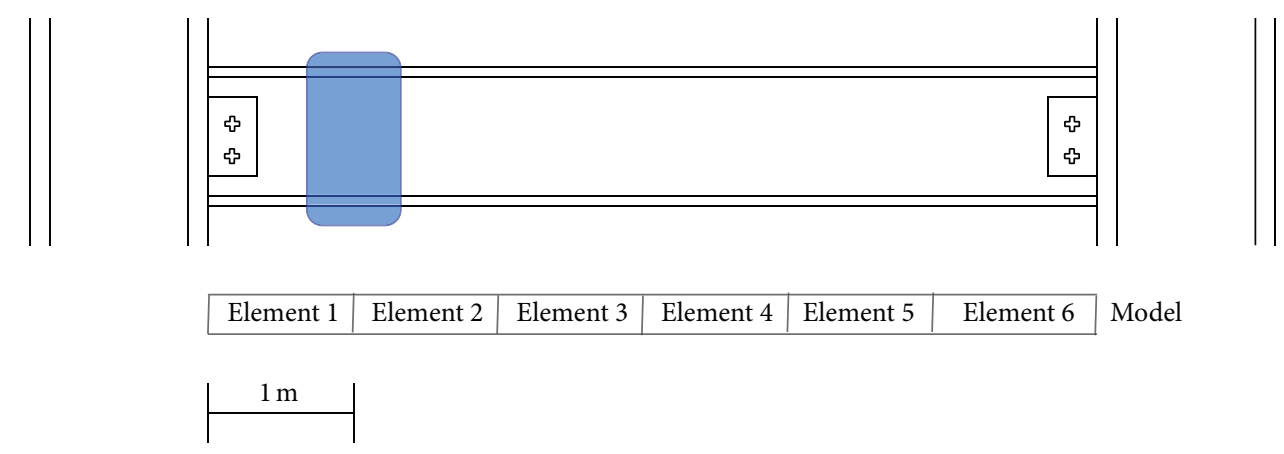

FIGURE 3: Single damaged structure and model.

TABle 5: Assumed and identified rotational stiffness for multiple damage case.

\begin{tabular}{lcccc}
\hline & $\begin{array}{c}\text { Rotational stiffness at } \\
\text { right end of element 1 }\end{array}$ & $\begin{array}{c}\text { Rotational stiffness at } \\
\text { left end of element 2 }\end{array}$ & $\begin{array}{c}\text { Rotational stiffness at } \\
\text { right end of element 5 }\end{array}$ & $\begin{array}{c}\text { Rotational stiffness at } \\
\text { left end of element 6 }\end{array}$ \\
\hline Assumed values $(\mathrm{kN} \cdot \mathrm{m} / \mathrm{rad})$ & 147.60 & 147.60 & 147.60 & 147.60 \\
Identified values $(\mathrm{kN} \cdot \mathrm{m} / \mathrm{rad})$ & 165.41 & 165.41 & 151.35 & 146.66 \\
Error $(\%)$ & 10.16 & -12.06 & -2.54 & 0.63 \\
\hline
\end{tabular}
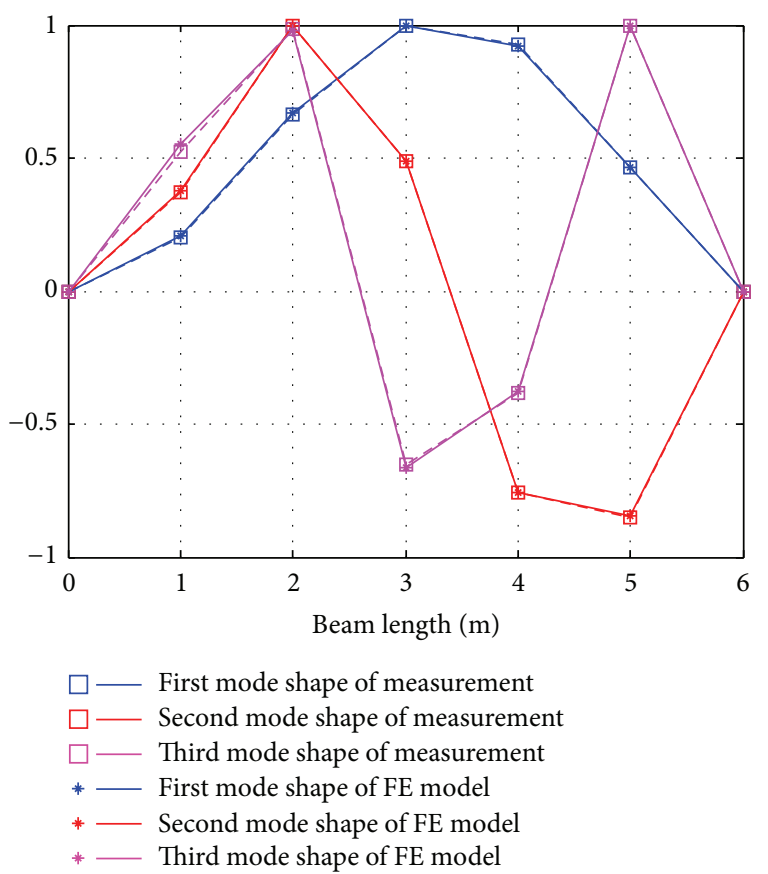

FIGURE 4: Comparison of mode shapes from measurements and updated model for single damage case.

searching conditions such as numbers of population and chromosome of NSGA-II to single damage case were used, although parameters to be identified increased in multiple damage case. According to the number of parameters to be identified, search resolution of NSGA-II needs to be adjusted to obtain accurate result.

From the dynamic characteristics after damage, it is found that the natural frequency values became lower compared
TABLE 6: Comparison of natural frequencies from measurements and updated model for multiple damage case.

\begin{tabular}{lccc}
\hline & First mode & Second mode & Third mode \\
\hline Measurements (Hz) & 77.43 & 181.22 & 340.65 \\
Updated model (Hz) & 77.51 & 180.68 & 341.79 \\
Error (\%) & -0.10 & 0.30 & -0.33 \\
\hline
\end{tabular}

to the single damage case. The modal parameters from measurement and the model updated with the identified damage information for multiple damage case are given in Table 6 and Figure 6 . The modal parameters of the updated model precisely matched the measured parameters.

\section{Conclusions}

This paper proposed a damage detection technique for the cold-formed steel structural member and was validated through a simulation. Local buckling was assumed to occur when the cold-formed beam was damaged, and the model would exhibit semirigid joint behavior between elements at the corresponding locations. The variables for the damage detection technique were set to the damage location and the rotational stiffness of the semirigid joint to represent the severity of the damage. The error functions were set to the differences of modal parameter between measurement and model. The functions were minimized by NSGA-II, which is a multiobjective optimization technique. The proposed technique was validated through a simulation to detect the damage to a cold-formed steel beam structure for single and multiple damage cases. The proposed technique identified the damage locations precisely. The result of comparison for the modal parameters obtained from the measurements and from the model updated with identified damage information 

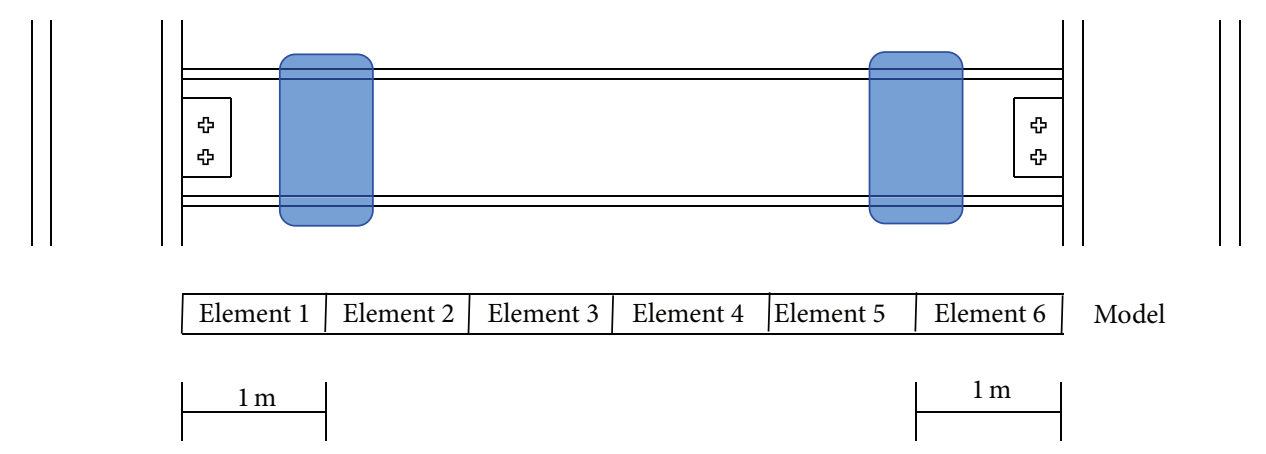

FIGURE 5: Multiple damaged structures and model.
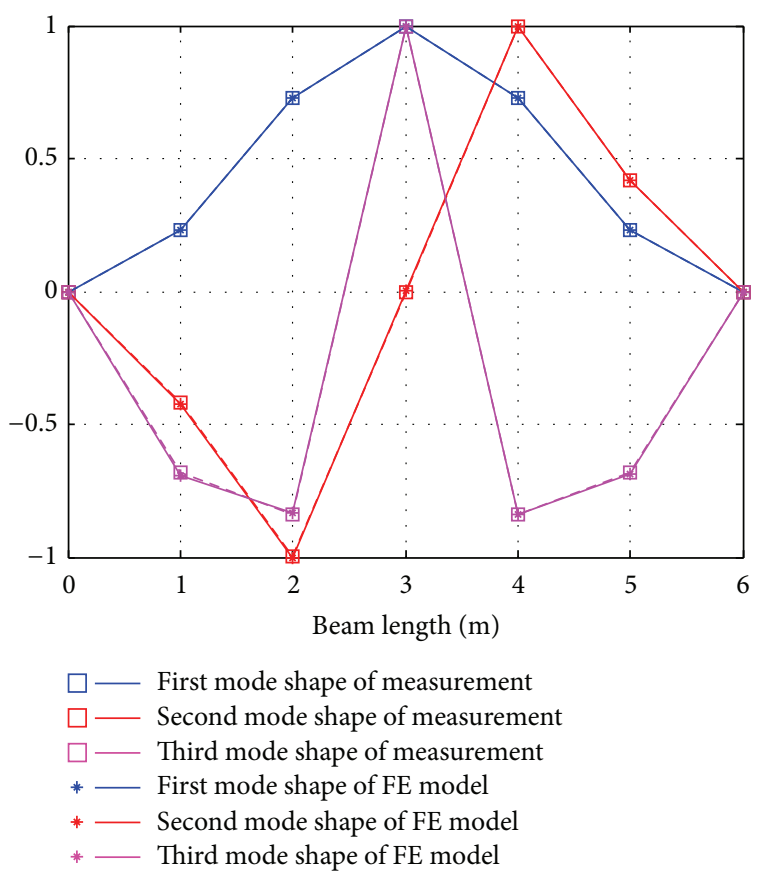

FIGURE 6: Comparison of mode shapes from measurements and updated model for multiple damage case.

showed considerable agreement. For the single damage case, the rotational stiffness, which denotes the severity of damage, was identified precisely. However, there were some errors in the multiple damage case. The error may have increased with the number of parameters during damage detection. The error problem can be solved by improving the solution search capacity of the minimization technique employed for damage detection in the future research.

\section{Conflict of Interests}

The authors declare that there is no conflict of interests regarding the publication of this paper.

\section{Acknowledgment}

This work was supported by the National Research Foundation of Korea (NRF) grant funded by the Korea government (Ministry of Science, ICT \& Future Planning (MSIP)) (no. 2011-0018360).

\section{References}

[1] H. M. Lee, S. W. Choi, D.-J. Jung, and H. S. Park, "Analytical model for estimation of maximum normal stress in steel beamcolumns based on wireless measurement of average strains from vibrating wire strain gages," Computer-Aided Civil and Infrastructure Engineering, vol. 28, no. 9, pp. 707-717, 2013.

[2] S. W. Choi, J. H. Lee, B. H. Oh, and H. S. Park, "Measurement model for the maximum strain in beam structures using multiplexed fiber bragg grating sensors," International Journal of Distributed Sensor Networks, vol. 2013, Article ID 894780, 9 pages, 2013.

[3] H. Tam, H. Y. Au, K. M. Chung et al., "Distribution optical sensor system on the 610-m Guangzhou new TV tower," in Proceedings of the Optical Fiber Communication Conference, Los Angeles, Calif, USA, 2011.

[4] H. S. Park, Y. Shin, S. W. Choi, and Y. Kim, "An integrative structural health monitoring system for the local/global responses of a large-scale irregular building under construction," Sensors, vol. 13, no. 7, pp. 9085-9103, 2013.

[5] R. Brincker, L. Zhang, and P. Andersen, "Modal identification of output-only systems using frequency domain decomposition," Smart Materials and Structures, vol. 10, no. 3, pp. 441-445, 2001.

[6] A. Devin and P. J. Fanning, "The evolving dynamic response of a four storey reinforced concrete structure during construction," Shock and Vibration, vol. 19, no. 5, pp. 1051-1059, 2012.

[7] R. Jafarkhani and S. F. Masri, "Finite element model updating using evolutionary strategy for damage detection," ComputerAided Civil and Infrastructure Engineering, vol. 26, no. 3, pp. 207-224, 2011.

[8] R. Perera, R. Marin, and A. Ruiz, "Static-dynamic multi-scale structural damage identification in a multi-objective framework," Journal of Sound and Vibration, vol. 332, no. 6, pp. 14841500, 2013.

[9] V. H. Nguyen, J. Mahowald, S. Maas, and J.-C. Golinval, "Use of time- and frequency-domain approaches for damage detection 
in civil engineering structures," Shock and Vibration, vol. 2014, Article ID 872492, 9 pages, 2014.

[10] A. P. C. Duarte and N. Silvestre, "A new slenderness-based approach for the web crippling design of plain channel steel beams," International Journal of Steel Structures, vol. 13, no. 3, pp. 421-434, 2013.

[11] V. Z. Meimand and B. W. Schafer, "Impact of load combinations on structural reliability determined from testing cold-formed steel components," Structural Safety, vol. 48, pp. 25-32, 2014.

[12] K. Deb, A. Pratap, S. Agarwal, and T. Meyarivan, "A fast and elitist multiobjective genetic algorithm: NSGA-II," IEEE Transactions on Evolutionary Computation, vol. 6, no. 2, pp. 182197, 2002. 

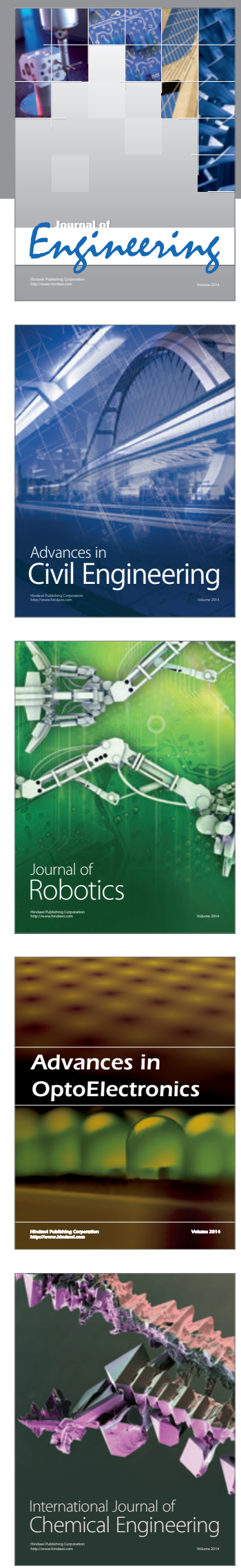

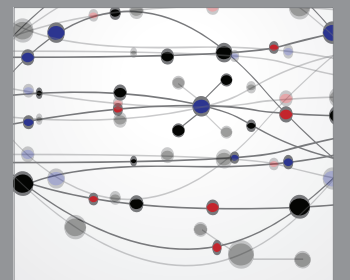

The Scientific World Journal
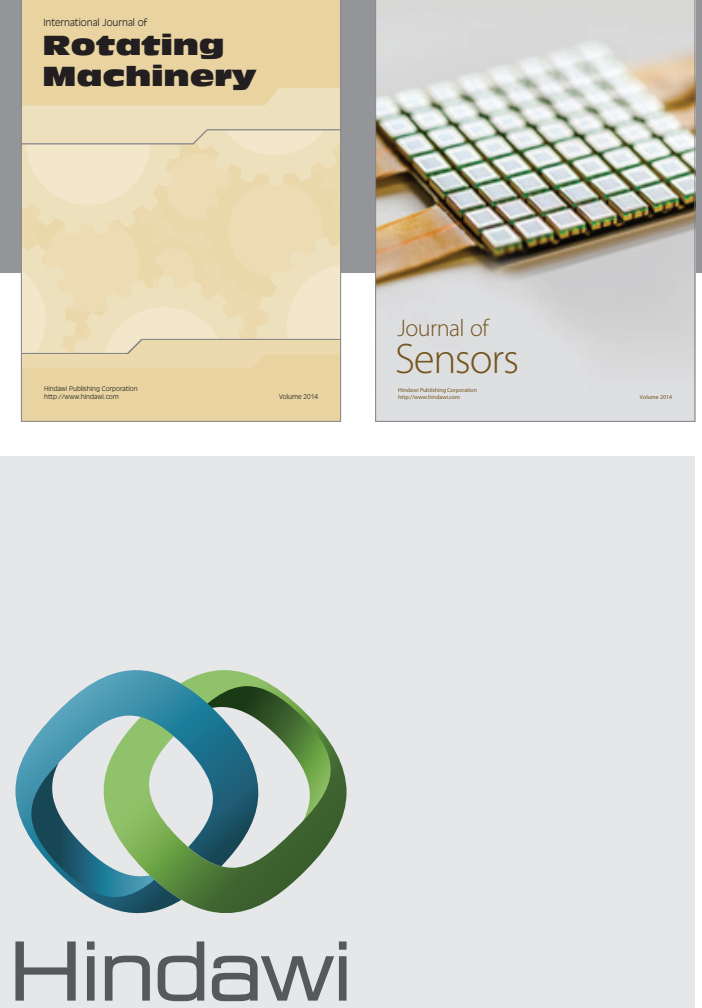

Submit your manuscripts at http://www.hindawi.com
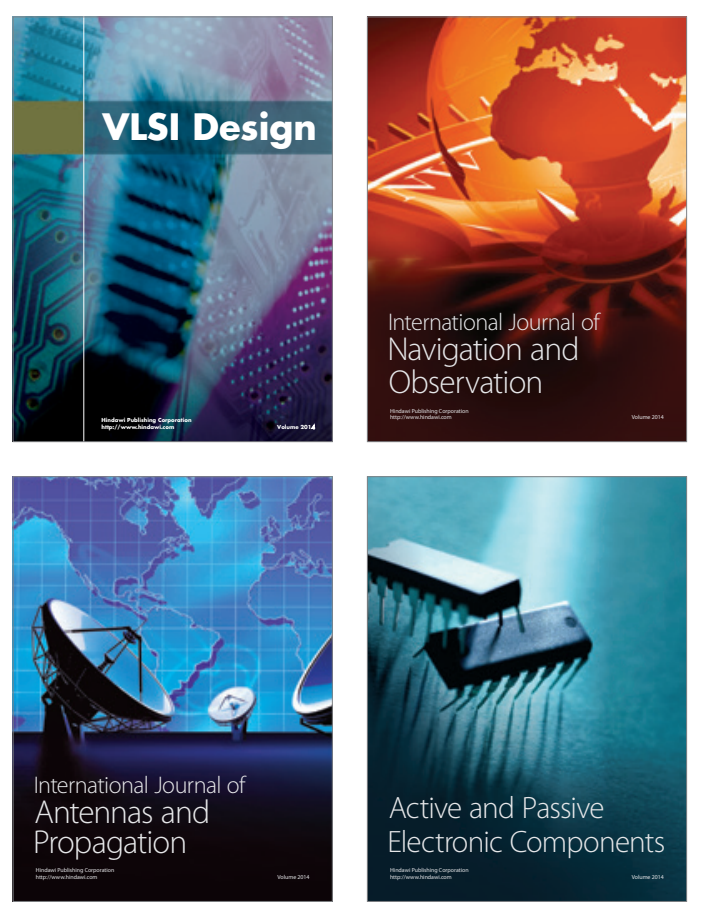
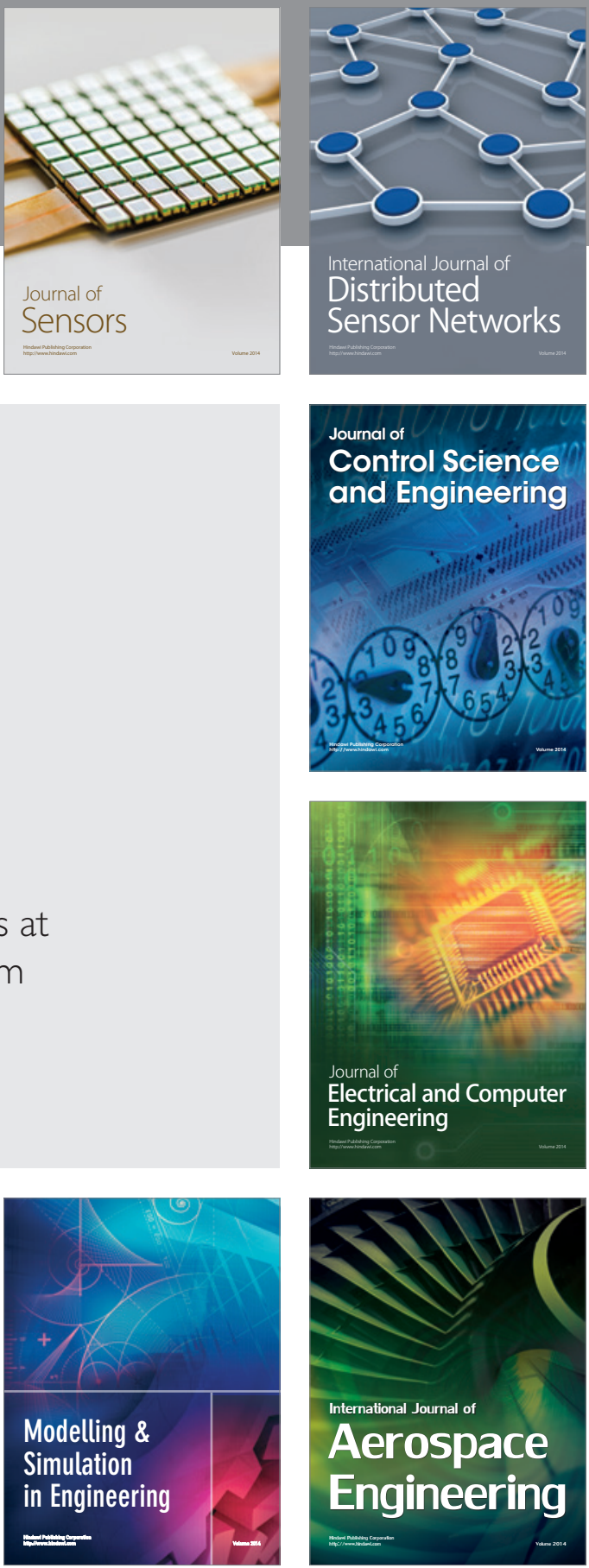

Journal of

Control Science

and Engineering
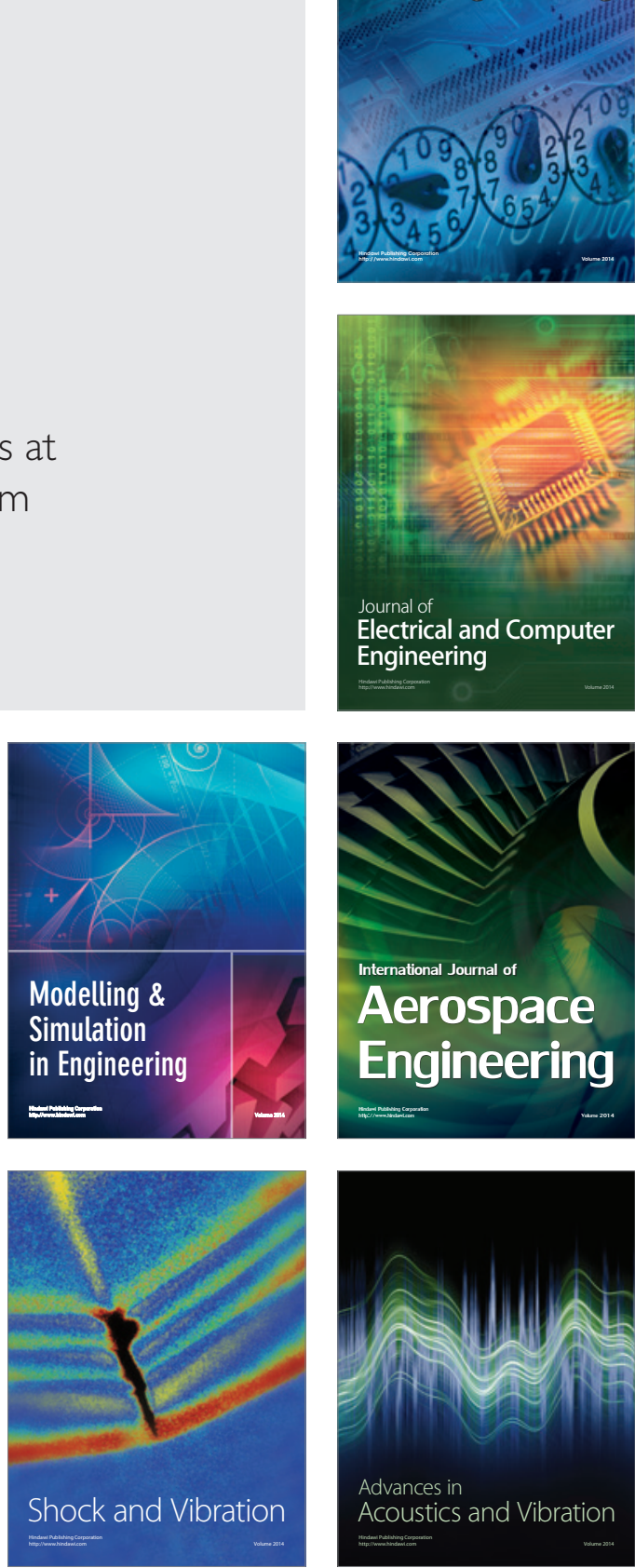